\title{
FМСG-РИТЕЙЛ: ОСОБЕННОСТИ КАТЕГОРИЙНОГО МЕНЕДЖМЕНТА В УСЛОВИЯХ ОБНОВЛЕНИЯ ПОВЕДЕНЧЕСКИХ ПАТТЕРНОВ ПОТРЕБЛЕНИЯ, РОСТА ОНЛАЙН-ПРОДАЖ, УСЛОЖНЕНИЯ ТОВАРНОЙ ДИФФЕРЕНЦИАЦИИ И ЦИФРОВОГО ИЗМЕНЕНИЯ БИЗНЕС-МОДЕЛЕЙ ТОРГОВОГО БИЗНЕСА
}

\author{
(c) 2021 Богатырь Владимир Михайлович \\ аспирант кафедры мировой экономики и международных экономических отношений \\ Донской государственный технический университет, Россия, Ростов-на-Дону \\ E-mail:Bvm7@mail.ru \\ (c) 2021 Михайлюк Михаил Владимирович \\ доктор экономических наук, доцент, \\ профессор кафедры логистики и управления транспортными системами \\ Ростовский государственный университет путей сообщения, Россия, Ростов-на-Дону \\ E-mail: Mihailuk.M@gmail.com
}

В статье авторы затрагивают широкий пласт изменений в работе торговых сетей от консолидации предложения в товарных категориях и перехода FMCG-ритейла к многоканальной модели продаж до формирования новых паттернов потребительского поведения в условиях общей деформации потребительской базы рынка. Эмпирически артикулированы и научно обоснованы отдельные примеры и способы управления товарными категориями, брендинга и потребительски ценной дифференциации в контексте сложившихся инструментов маркетинга, а также возрастания роли цены, что сокращает ценность УТП как основы дифференциации при общем ослаблении ценностнодифференцирующей базы товарной категории. Авторы выделяют перспективы многоканального сопряжения стационарного сбыта и онлайнового канала продаж при расширении количества товарных категорий как нового системного императива более результативного сбора покупательского трафика в стационарной и цифровой среде FMCG-рынка.

Ключевые слова: товарная категория, категорийный менеджмент, бренд, брендинг, дифференциация, стратегии, цена, ценовая эластичность.

Революция в торговле как знаковое изменение сферы товарного обращения России в условиях прихода и экспансивного роста торговых сетей в 2000-х гг. формировала мейнстрим научно-практических исследований этого периода [13]. Не менее сложная институциональнорыночная эволюция процесса повлекла за собой широкий спектр научных работ, посвященных развитию дисбалансов в переговорных позициях поставщиков и сетевого ритейла, перераспределению рыночной власти в цепях поставок потребительского рынка, и, связанному с этим смещению центра накопления стоимости (прибыли) в торговлю. Эмпирически укоренившееся давление торговли на товарный сектор экономики привело к формированию их новой межотраслевой конфигурации, перетоку все большей части добавленной стоимости в торговлю [13].

Современный период развития последней связан с еще большим изменением торгового бизнеса в связи с переходом все большей части потребительского спроса в онлайн, которое создает новый и мощнейший крен в развитии FMCG-ритейла.

Происходят широкополосные изменения в развитии сетевой розницы, которая начинает более активно развивать цифровой канал продаж, подкрепляя это увеличением инвестиций в онлайновую часть сбытовой цепочки.

Так, снижение интереса покупателей к крупным форматам FMCG-розницы вызвало существенное замедление развития «Ленты» и «О Кей», которые в 2019 г. показали прирост выручки соответственно на 7,3\% и 5,9\% (+1\% и +3\% в 2019 г.), что вдвое меньше динамики роста X5 Retail Group и «Магнит» по итогам 2020 г. (+13,3\% и +9,5\% соответственно): значительная часть товарооборота последних обеспечена магазинами формата «у дома». Этот факт связан с взрывными темпами роста дискаунтеров «ДА!» 
ГК «О Кей» - «последние за 2020 г. показали прирост выручки на 45,3\%, в то время как оборот магазинов «О Кей» увеличился всего на 1\%» [19, с. 7].

Оценивая общий стратегический вектор трансформации крупных сетей FMCG-ритейла можно констатировать, что он состоит в непрерывном приближении кпотребителю, ускорению и упрощению процесса совершения покупки. Маркерами этого выступают онлайн-торговля и формат шаговой доступности как новые драйверы масштабирования сетевой розницы. Так, X5 Retail Group в условиях ковидных ограничений запустил экспресс-доставку из магазинов сети, которая дополнила сервис «Перекресток Впрок» расширив его доступность до 13 регионов, а также сервис «Около», который объединил в одном приложении возможность заказа из локальных магазинов X5 Retail Group, включая «Карусель». По итогам 2020 г. X5 Retail Group лидировал по выручке онлайн-канала (13,3 млрд. руб. в 2020 г. против 4,3 млрд. руб. в 2019 г.), доля которого выросла с 0,2\% в 2019 г. до 0,7\% в 2020 г. [9, с. 13]. Развитие онлайн-канала потребовало от оператора расширения автопарка на 20\%.

Сеть «Магнит» также запустила е-commerce проекты в стадии пилота: во второй половине 2020 г. возможность онлайн-заказа и экспрессдоставки (совместно с Delivery Club и «Яндекс. Еда») была расширена до гипермаркетов г. Краснодара. «По данным на февраль 2021 г. сервисы e-commerce «Магнита» охватывают более 1 тыс. магазинов сети в 47 регионах и 72 городах. При этом 50\% выручки онлайн-сегмента ретейлера генерируются за пределами Москвы и СанктПетербурга» [19, с. 13].

Максимальный прирост онлайн-продаж по итогам 2020 г. показал оператор «Лента»: выручка от е-commerce выросла в 6 раз и достигла 6,3 млрд. руб. против 1 млрд. руб. в 2019 г. (доля онлайн-продаж в обороте сети возросла с 0,2\% до $1,4 \%)$.

Таким образом, пандемия ускорила развитие онлайн-продаж и сервисов доставки при активном расширении географии последней, а также добавлении новых логистических сервисовпартнеров. Фокус в развитии доставки ритейлеров определялся концентрацией магазинов сетей в различных локациях.

Все это позволяет констатировать, что экстенсивный рост и органическое расширение розничных сетей по территориям, их активное пространственное расширение постепенно по- теряли актуальность в новой рыночной реальности. Пандемия, а также хроническое ослабление спроса (реально располагаемые денежные доходы населения не растут с 2013 г.) создали новый рыночно-экономический контекст, в котором сети вынуждены пересматривать стратегические планы по расширению розницы. Новым императивом их стратегической трансформации становится отход от количественного роста офлайна в условиях общего кризиса крупных форматов продовольственной розницы и ставка на качественное изменение розничного бизнеса.

Деформация потребительской базы рынка, переток части спроса в масс-маркет, характерный также для кризиса 2008 г. и 2014 г. сформировали новую специфику управления товарными категориями продукции, маркетинг продаж которой значительно изменился. Разберем основные из этих изменений, определив их предпосылки и условия.

Во-первых, в условиях слабого спроса ценовой демпинг в рамках целевой группы товаров первой необходимости достиг своего предела. Заметим, что развитие онлайн-ритейла только усилило этот тренд с переносом на дорогие товары (бытовая техника, потребительская электроника), что привело к давлению на рентабельность ритейла и поставщиков. В развитии бизнеса все большее значение приобрела стратегия лидерства по издержкам. Это потребовало максимального включения эффекта масштаба, ликвидации всех лишних издержек, разворота и оптимизации бизнес-моделей. Торговые сети вновь обратились к промо- и акционным активностям, запускали кросс-маркетинговые активности с поставщиками и т.д.

Важно отметить, что высокий уровень эластичности спроса, который удерживается на рынке в течение длительного периода времени сильно снизил потенциал продуктовой и маркетинговой дифференциации на торговых полках. Примечательным является тот факт, что к акциям с глубокой скидкой прибегают производители премиального сегмента (например, соки «Rich»), что впервые было зафиксировано на российском рынке в кризис 2008 г., когда перед угрозой низкого спроса маркетинг значительной чести ритейла и производителей оказался практически бессилен. Теоретически рафинированное понятие «лояльность» оказалось сложно эксплуатировать, поскольку потенциал маркетинговой дифференциации и приверженности 
отдельным брендам резко «сошел на нет». С нашей точки зрения данная проблема сегодня не утратила своей актуальности в управлении товарными категориями, где возможность извлечения или удержания высокого уровня ценовой премии становится все меньше.

Во-вторых, снижение покупательской активности приводит к общей стагнации рынка в разрезе отдельных товарных категорий, сокращению физического объема продаж в расчете на товарный артикул. В этих условиях бизнес начинает искать новые способы увеличения прибыли, выбирая из них два основных:

- сокращение издержек;

- дополнение действующих каналов сбыта неродственными товарными категориями.

Сокращение издержек представляет собой классическую маркетинговую стратегию, наиболее востребованную в недорогих товарных сегментах. B FMCG-ритейле высокой ценовой конкурентоспособности достигают несколько крупных поставщиков на консолидированных рынках, которые за счет эффекта масштаба могут сократить удельные издержки на единицу продукции. В более широком научно-практическом плане можно отметить развитие теории «подрывных инноваций» К.Кристенсена, которая наиболее востребована с современных условиях. Суть стратегий подрывных инноваций сводится к усечению лишнего функционала продукта, за который потребитель не готов платить и его предложение на рынке по более привлекательной - низкой цене. Как отмечает К. Кристенсен, «когда мир потребителей осмысляется в терминах продуктов и их атрибутов, инноваторы пытаются обогнать конкурентов за счет ничего не значащих для потребителей функций и стиля» [10, с. 101]. Такая логика построения продукта сегодня востребована на рынке и открывает широкое поле для конкурентного развития подрывных инноваций во многих товарных категориях. Можно подчеркнуть теоретическую перекличку данной теории с инновационной концепцией конкуренции Рене Моборна и В.Чан Кима, «голубые океаны» которых предлагают более сложную схему переворота стратегической канвы ценности продукта, при котором делается векторный разворот - отступ от акцентов на традиционном развитии функциональных свойств продукта, бизнеса или бизнес-модели.

Неродственная диверсификация в товарных категориях представляет собой более мощный инструмент изменения не только продукта, но и бизнес моделей современной сетевой розницы. Толчковая точка этого подхода сегодня апеллирует к новым паттернам потребительского поведения, когда товарное многообразие становится более привлекательным как в офлайне, так и в онлайне. В стационарной торговле это привело сначала к отмиранию street-ритейла и ослаблению рыночного потенциала специализированной розницы в целом, когда посещение отдельно стоящего продовольственного магазина становится более сложным для потребителя. Затем мы увидели новый тренд, связанный с переходом конкуренции на рынок торговой недвижимости, которая к 2020 г. начала развиваться под знаком реконцепции торговых центров (ТЦ), которые активно расширяющих фудкорты и развлекательную часть ТЦ.

Развитие онлайн-ритейла привело не только к переходу стационарных розничных сетей в digital, но и подключению к своей товарной матрице неродственного ей ассортимента, что больше отвечает интересам современного потребителя, который заходит на цифровую платформу. Например, в сегменте онлайн-банкинга пионером, успешно пилотировавшим и развившим этот подход, выступает Тинькофф-банк, который прошел длинную эволюцию, завершив цепочку своих цифровых итераций переходом к развитию «life-style банкинга». В развитии непродуктовой сетевой розницы релевантным примером неродственной диверсификации является OR Group (ГК «Обувь России»), которая сегодня активно трансформирует свою бизнесмодель fashion-ритейлера и превращается в универсальную торговую платформу. Принимая оплату ЖКУ в торговых точках сети как доп. способ получения прибыли, OR Group «создает принципиально новую систему универсального омниканального магазина - формат, который включает в себя сеть розничных точек и маркетплейс под брендом Westfalika» [9, c. 25].

Этот процесс сопровождается добавлением к обуви неродственного ассортимента одежды, товаров для дома и др. Именно мультикатегорийное предложение становится важной точкой конкурентного отличия онлайн-ритейла от классической розницы, что обеспечивает им универсальность, больший охват целевой аудитории и увеличение выручки за счет добавления товарных категорий. Здесь возникает важная высоко монетизированная синергия с офлайно- 
вой сетью торговых точек ритейлера, которые сегодня трансформируются в партнерские пункты выдачи заказов. С одной стороны, это позволяет обеспечить дополнительную прибыль, которая будет потеряна при работе OR Group в чисто стационарном формате. С другой, взаимодействие с крупными маркетплейсами, поставщиками, а также логистическими операторами при запуске интегрированных пунктов выдачи заказов (ПВЗ) дает более эффективную экономику затрат ПВЗ: генерируется кратно больший объем трафика и посылок на одну точку, особенно в небольшом населенном пункте. Сохраняющийся в инфраструктуре логистики последней мили дефицит, особенно при ее региональном расширении создает предпосылки дальнейшего объединения участников рынка, которое может быть монетизировано одним из них.

То есть, мультикатегорийный менеджмент становится функцией или инструментом в системе более глубоких отраслевых изменений современного ритейла, связанных с переходом в онлайн и более сложным разворотом бизнесмодели, реализацией решений, на стыке которых достигается новая более рентабельная экономика продаж. Именно этот институционально связный и широкий спектр изменений формирует проблемный контекст настоящего исследования, который выводит его за рамки экономически «усеченного» - традиционного определения категорийного менеджмента.

В-третьих, высокая скорость органического роста FMCG-ритейла приводит к насыщению рынка стационарной розницы, когда охват территорий магазинами шаговой доступности становится более высоким. Это приводит к сокращению выручки в расчете на торговую точку. Кроме того, кризис крупных форматов сетевой розницы означает снижение эффективности продаж в силу возрастания издержек на 1 рубль выручки в форматах более «мелкой нарезки» сетевой розницы. Такая ориентированная на потребителя перестройка FMCG-сетей создает давление на рентабельность продаж. Это усиливает ценовое давление на поставщиков, создавая предпосылки для более сильной и прибыльной дифференциации их предложения в различных товарных категориях. Эмпирическая «отработка» такой дихотомии является крайне сложной на отдельных рынках (сахара, молока и др.) где рентабельность продаж последние годы находится на около нулевом уровне. При этом, кон- солидация рынков, например, мяса и мясо-колбасной продукции также затрудняет рост более мелких компаний, которые могут рассчитывать только на более дискретную отгрузку в несетевую розницу. Это означает более затратную логистику, ограниченность объемов сбыта и торговой наценки, что будет вести к еще большей консолидации рынка.

В-четвертых, следует отметить лояльность современного потребителя к скидкам и акциям, что ослабляет инструментарий современного брендинга. Это существенно изменяет маркетинг FMCG-ритейла, который сегодня ограничен в возможностях перевести в прибыль конкурентные отличия, построенные на ценностях и значениях бренда. Наиболее сильно это проявляется по отношению к «В2В»-потребителю, где роль и значение цены являются более высокими. В товарных категориях, ориентированных на потребительский сегмент рынка эмоциональные ассоциации трудно скопировать, но можно заместить менее дорогим брендом с «одинаковыми» функциональными ассоциациями. В линейке непродовольственных товаров, внедрение технологий, которые ускоряют, упрощают и удешевляют инновации, приводит к переключению с инновации на имитацию. Как отмечает Ловелл Н., «доминированию товаров массового рынка приходит конец. Технология позволяет осуществлять массовую персонализацию всего: от автомобиля за 30000 долл. до куклы за 100 долл. или даже запонок за 10 долл.» [11, с. 94]. Возрастающая сложность дифференциации, скорость внедрения инноваций только ускоряют выход и закрепление - позиционирование брендов, конкурентное отличие которых должно иметь «внятную» потребительскую ценность. В противном случае потребители оценивают привлекательность по ценовой доступности бренда, что характерно практически для всех товарных категорий. Происходит «перемещение» бренда на второе место после таких инструментов как стоимость и ценообразование. Масштаб изменений в рамках даже признанных категорий продукции, создаваемых рынком, является незначительным при том, что существенным является изменение их медиасопровождения, при котором изобилие рекламы сосуществует с дефицитом смысла и потребительской ценности для клиента. То есть, имеет место ослабление маркетинговой функции бренд-стратегий. На наш взгляд, в условиях слабого высокоэластичного 
спроса брендинг товарных категорий повышает лояльность целевой аудитории, не создавая значимых сопряженных с ним экономических эффектов извлечения ценовой премии и роста прибыли: экономика конкурентных отличий и ценностной дифференциации как основания сложного и стратегически продуманного брендинга не является достаточно эффективной.

Это создает пятую особенность управления товарными категориями, связанную с возрастанием схожести продукции. В разных товарных категориях, от автомобилей до продуктов питания и бытовой химии, строительных материалов и инструментов брендинг строится на предложении разной упаковки продукции, имеющей схожий функциональный базис, свойства и состав. «Разгон» технологий и дизайна вывел качество на уровень, где сложно обеспечить его скачкообразный функциональный прирост, создающий реально ценную для потребителя прибылеобразующую дифференциацию. При этом происходит затратоемкий сдвиг основания конкуренции, когда важной становится, например, скорость обновления продуктовой линейки, что «объемно» видно на примере автомобилей.

С другой стороны, однородность товарных категорий усиливает сам маркетинг, который фокусируется не на создании брендов, а на их размывании. Как отмечает Д.Траут, акцент на развитие программ продвижения становится избыточным: «производители под давлением собственных сбытовых подразделений и крупных розничных торговцев вкладывают средства не в создание брендов, а в ценовые программы продвижения» [20, с. 35]. Это концентрирует внимание потенциального покупателя на выгоде от сделки, а значит уводит от самого бренда. Передача маркетинга на сторону дополняет это избыточным применением технологий и эффектов, создающих привлекающее внимание CTA (callto-action), что делает рекламный «мессенджер» менее дифференцирующим бренд, но создающим необходимый уровень виральности. Тем самым, в практике маркетинга товарных категорий создается отступ от классических стратегий дифференциации (Д.Траут выделяет пять), которые по мнению гуру маркетинга из Гарвардского университета Т.Левитта «Маркетинговая миопия» («The marketing Imagination») позволяют дифференцировать и создать УТП практически для любого класса продукции. С другой стороны, крупные поставщики на сильно кон- солидированных рынках для входа в FMCG-сети могут работать без УТП, срезать все лишние издержки (отсечение ценности как инструмент дифференциации), включать эффект масштаба и предлагать самый дешевый продукт или продукт с минимальным балансом «цена/ценность». В условиях слабого спроса данная стратегия без УТП с отсутствием целевой аудитории позволяет занять значительную долю рынка, равно как и в развивающихся товарных категориях и/или продуктовых сегментах с низким уровнем культуры потребления.

В целом, можно констатировать, что бренд «перемещает» продукт в более высокий стоимостной диапазон ценообразования, но его потребительская емкость сегодня сжимается. Начало этому процессу было системно положено в кризис 2008 г., когда впервые была отмечена миграция спроса в нижние ценовые сегменты рынка, а отечественный маркетинг показал «аномальную» беспомощность, массово сводя программы лояльности к акциям и скидкам. Деформация потребительской базы рынка при хронической стагнации доходов домохозяйств создает повышенную ценовую эластичность спроса. Данная слабость потребления сталкивается с расширенной марочной структурой предложения товарных категорий, где «бренды становятся более узнаваемыми и в тоже время менее дифференцированными в сознании потребителя» [8, с. 102]. Такое сложное сопряжение спроса и предложения резко актуализирует вопрос о реально достижимой дифференциации брендов в определенной товарной категории или индустрии. Это позволяет эмпирически констатировать системно-эволюционные подвижки в конъюнктуре современного товарного рынка, не переводя наши рассуждения в плоскость диагностики сугубо маркетинговых ошибок «линейного расширения» и др., «анатомированных» классиками американского маркетинга Д. Траутом, Э.Райсом и др. $[18,20]$ По сути, происходит снижение качества рыночной упаковки торгового предложения товарных категорий, когда умножение роли цены изменяет маркетинговые акценты, выдавливая ценность УТП как основы дифференциации, которая не может быть замещена низкой стоимостью продукции. В итоге, по М.Портеру мы имеем как минимум тактический переход к стратегии «лидерства по издержкам» с ослаблением потребительской релевантности ценностно-дифференцирующей 
базы товарной категории.

Как шестую особенность можно отметить развитие отраслевых рынков и концентрацию капитала, что приводит к изменению парадигмы ценообразования, когда цена продажи и глубина дисконтирования сильно зависят от объема. Происходит ресегментирование потребителей, особенно «В2В»-клиентов, наиболее крупные их которых дешево и объемно закупаются - генерируют ликвидность (вал продаж), остальные покупают с меньшей скидкой, образуя более маржинальную часть выручки (прибыль). Важно отметить, что развитие отраслевых бизнесов сокращает «хвост рынка» (в терминах К.Андерсона), что будет постепенно выравнивать скидку, повышая ее минимальный уровень (данная ценовая балансировка является неодинаковой для разных товарных категорий).

Обобщение обозначенных нами выше особенностей применительно к FMCG-ритейлу означает более точечное проецирование сформулированных нами выводов на специфику сбыта продукции через торговые сети, где перепроизводство ужесточило конкуренцию и ликвидировало дефицит ассортимента для ритейла, характерный на заре его рыночного взросления (начало 2000-х гг.). Как отмечает А.Горнов, «торговой сети не интересно, что ваш продукт уникален или произведен с помощью какой-то уникальной технологии. Для ритейлера важно только то, за что потребитель голосует рублем» [4, с. 270]. Высокое качество также перестает быть аргументом, поскольку некачественной продукции в сетях нет. Большие инвестиции в производство и продукт требуют соразмерных вложений в маркетинг и коммуникацию с потребителем, что в сумме должно обеспечить релевантную статистику продаж и оборачиваемость SKU на торговой полке.

Монополизация торгового пространства FMCG-сетями превращает их в канал массового прокачивания товарной массы через потребительский рынок. Это приводит к быстрой ротации поставщиков, которые не обеспечивают необходимую скорость и емкость продаж. Сильная переговорная позиция сетей приводит к постоянному «продавливанию» поставщика по цене, что требует от него формирования определенного запаса по марже и возможно только через сильную дифференциацию и брендинг, завязанные на конкурентный УТП. Этот тезис системно резонирует с общим лейтмотивом сделанных нами выше выводов. В практике FMCG-продаж он верифицируется более жесткими реалиями рыночной конкуренции в товарных категориях, где более крупные поставщики могут держать цену ниже себестоимости в борьбе за долю рынка и расширение полочного пространства в сети, что обеспечивает им рост стоимости акционерного капитала и потенциальную прибыль в долгосрочной перспективе.

Все это указывает на то, что проработка вопросов брендинга, формирования УТП и ценной для потребителя дифференциации должна происходить до входа в торговую сеть: помещение товара на торговую полку создает уже рычаг монетизации маркетинговых решений для поставщика. Позволяет поддерживать и достигать роста доходности его товарной категории, надежно купировать риски невыполнения КPI категорийного менеджера сети.

При этом избыточное укрепление отдельных брендов на торговой полке создает риски ослабления переговорной позиции ритейлеров, которые «хорошо относятся к возможности ослабить позицию звездных брендов», в том числе путем запуска собственной торговой марки (СТM) в упаковке, идентичной популярному бренду [4, с. 274].

Таким образом, мы имеем континуум условий и решений, движение поставщика по которому должно обеспечить ему высокий уровень конкурентоспособности, неценовой дифференциации и позиционирования на рынке и в полочном пространстве FMCG-ритейлера.

В целом, в статье нами рассмотрен спектр изменений, связанных с развитием цифрового направления продаж, расширения количества товарных категорий и включения дополнительных источников формирования прибыли, что приводит к развороту традиционных бизнесмоделей торгового бизнеса, результирующую конфигурацию которых сегодня сложно спрогнозировать. Формируется новая рыночная логика построения мультикатегорийного менеджмента на стыке онлайна и офлайна, изменение функции стационарных торговых точек и перехода узкоспециализированного ритейла к многоканальной модели универсальных торговых площадок, более объемно и эффективно абсорбирующих покупательских трафик. 


\section{Библиографический список}

1. Белова Л. А., Верона Л. И. Современные тренды развития розничной торговли // Естественно-гуманитарные исследования. 2021. № 33 (1). С. 42-46.

2. Броско Ю. Brand Legend - 7 эффективных моделей для описания бренда / Юлия Броско. - [б.м.]: Издательские решения, 2019.

3. Горбачев А.М., Таушан И.В. Особенности развития систем менеджмента в сетевом ритейле // Территория науки. 2019. № 1. С. 25-29.

4. Горнов А. Метод Getbrand. Как начать продавать больше, создав свой сильный бренд: пошаговая инструкция / Андрей Горнов. - Москва, 2021.

5. Грив Г. Преимущества сетей: как изначально извлечь максимальную выгоду из альянсов и партнерских отношений / Генрих Грив, Тим Роули, Андрей Шипилов; пер. с англ. - М.: Альпина Паблишер, 2019.

6. Есина О.Н., Терещенко Н.Н., Ильина А.С. Диагностика ассортимента розничного торгового предприятия с учетом доходности продаж // Торговля, сервис, индустрия питания. 2021. Т. 1. № 1. С. 20-31.

7. Ибрагимхалилова Т.В. Интернет-торговля: формы, типы, стратегии // Инновационные векторы цифровизации экономики и образования в регионах России. Сборник научных статей по материалам Всероссийской научно-практической конференции. Ставрополь, 2021. С. 269-274.

8. Идрис М. Брендинг за 60 минут // Идрис Мути;[пер. с англ. В. С. Агеева]. - Москва: Издательство «Э», 2016.

9. Инкижинова С. Переобулись в экосистему // Эксперт. 2021. № 47. С. 24-29. (25).

10. Кристенсен К. Теория инноваций как инструмент предсказания отраслевых изменений / Клейтон Кристенсен, Скотт Энтони, Эрик рот.; Пер. с англ. - 4-е изд. - М.: Альпина Паблишер, 2017.

11. Ловелл Н. Кривая спроса. Как умные компании находят ценных клиентов. - СПб.: Питер, 2014.

12. Михайлюк, М.В.Демпинг и передел рынка как среднесрочное следствие будущего инвестиционного роста логистической инфраструктуры маркетплейсов в России // Интеграционные процессы в науке в современных условиях: сборник статей Международной научно-практической конференции (25 марта 2019 г, г. Оренбург). / М. В. Михайлюк. - Уфа: Аэтерна, 2019. С. 49-55.

13. Михайлюк М.В. Особенности современного развития системы товародвижения потребительского рынка: монография / М. В. Михайлюк. - Ростов н/Д: Издательско-полиграфический комплекс РГЭУ (РИНХ), 2017.

14. Михайлюк М.В. Тенденции и направления развития логистики торговых площадок в е-commerce России / М. В. Михайлюк // Общество. 2019. № 1 (12). С. 37-41.

15. Михайлюк М.В. Цифровая трансформация рынка: маркетинговые потенциал и институциональнорыночные особенности развития онлайн-продаж / М.В.Михайлюк // Экономика и предпринимательство. 2020. № 11. С. $725-728$.

16. Москвитина А. Э. Особенности рынка Интернет-торговли в России // Е-Scio. 2021. № 2 (53). С. $383-387$.

17. Попенкова Д. К. Стратегия развития категории товара ритейлером // Экономика и предпринимательство. 2020. № 2 (115). С. 1143-1154.

18. Райс Эл. Стратегия фокусирования: Специализация как конкурентное преимущество / Эл Райс: пер. с англ. М. Мацковской. - М.: Манн, Иванов и Фербер, 2014.

19. Сравнительный экспресс-анализ крупнейших публичных ритейлеров в сегменте FMCG: итоги 2020 // PБК: исследование рынков. Москва. 2021. [Электронный ресурс]: https://marketing.rbc.ru/research/44763/ (дата обращения: 01.11.2021 г.).

20. Траут Д., Ривкин С. Дифференцируйся или умирай. СПб., Питер, 2002. 